266

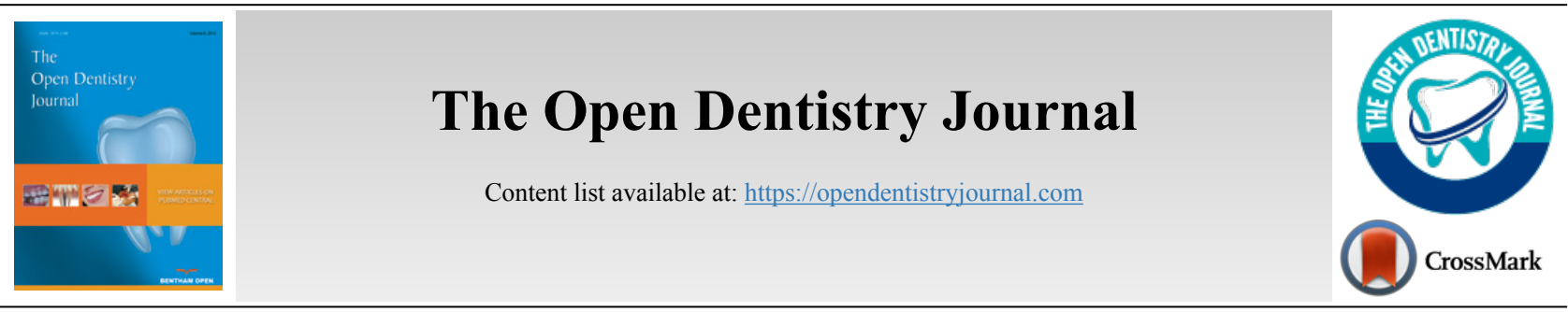

RESEARCH ARTICLE

\title{
The Correlation between Pain, Stress, and Oral Function in Oral and Maxillofacial Infection and Trauma Patients
}

\author{
Medyannisa Shafira $^{1}$, Tantry Maulina, ${ }^{2, *}$, Nurnayly Putri Lyana ${ }^{1}$, Endang $\operatorname{Sjamsudin}^{2}(\mathbb{D})$ and Andri Hardianto ${ }^{2}$
}

${ }^{1}$ Faculty of Dentistry, University of Padjadjaran, Bandung, Indonesia

${ }^{2}$ Department Oral Surgery, Faculty of Dentistry, University of Padjadjaran, Bandung, Indonesia

\begin{abstract}
:
Background:

The relationship between stress and acute pain has been documented in previous studies. Yet, very few studies have evaluated the relationship between stress and acute orofacial pain and its impact on jaw functional activities.

\section{Objective:}

The objective of the current study was to evaluate the correlation between acute orofacial pain, stress, and the limitation of the jaw and facial activities in oral and maxillofacial infection and oral and maxillofacial trauma patients.

\section{Methods:}

The current study recruited 50 (16 male, 34 female) patients from the Emergency Unit of the Ujung Berung Hospital, Bandung Indonesia. Twentyfive patients were those who had oral and maxillofacial trauma, and the rest were those who had an oral and maxillofacial infection. The patient's stress level was evaluated by measuring their salivary alpha-amylase level, the pain level was measured by using the numeric rating scale (NRS), whilst the limitation of the jaw and facial activities was measured by using the Jaw and Facial Activities Limitation (JFAL) Questionnaire. All data were analysed using the Spearman correlation test.
\end{abstract}

Results:

Based on the analysis, it was revealed that there was no significant correlation $(r=0.176, p=0.22)$ between stress and pain level. When associated with jaw and facial activities limitation, there was a significant positive correlation $(r=0.555, p<0.01)$ found between pain level and jaw and facial activity limitation.

\section{Conclusion:}

The current study concluded that there was a significant positive correlation found between pain and jaw activity limitation on oral and maxillofacial infection and trauma patients.

Keywords: Jaw functional activity, Orofacial pain, Psychological stress, Orofacial trauma, Orofacial infection, Salivary alpha-amylase.

\begin{tabular}{|l|l|l|l} 
Article History & Received: October 29, 2020 & Revised: February 25, 2021 & Accepted: March 20, 2021
\end{tabular}

\section{INTRODUCTION}

Orofacial pain is defined as pain that manifested in the facial and oral area [1]. Based on its etiology, orofacial pain can be classified into the odontogenic and non-odontogenic ori-

\footnotetext{
* Address correspondence to this author at the Department of Oral Surgery, Faculty of Dentistry, Universitas Padjadjaran, Jl. Sekeloa Selatan no. 1, Bandung 40132, Indonesia; Tel: +6282115513030;

E-mails: tantry.maulina@fkg.unpad.ac.id, tmau4292@uni.sydney.edu.au
}

gin, whilst based on its duration, orofacial pain can be categorized into acute orofacial pain and chronic orofacial pain. Even though chronic orofacial pain has a bigger impact on an individual's life due to its duration, acute orofacial pain is considered to be as impactful due to its high intensity [2]. Based on this classification, acute orofacial pain that involves the mouth, jaw, and face is one of the most complained types of orofacial pain [3]. In Indonesia, a study about the prevalence of orofacial pain conducted all across the province of West 
Java showed that the most experienced type of orofacial pain was of the odontogenic origin, which was dental pain $(67.5 \%)$ [4]. Another study conducted by Svensson showed the predominance of dental pain, as it was found as the most common orofacial pain experienced by patients $(77.6 \%)$ with high pain intensity [5]. In a study performed by Locket et al., it was revealed that dental pain was also the most complained orofacial pain with $50 \%$ of patients experiencing this type of pain, with moderate or severe pain intensity $[6,7]$.

In the field of oral surgery, the conditions that have the potential to cause acute orofacial pain are oral and maxillofacial infection, and oral and maxillofacial trauma. Oral and maxillofacial infection mainly manifests in the form of dental abscesses and is one of the most common causes of dental treatments [8]. It can be induced by several factors, such as dental caries, trauma, deep fillings, or failed root canal treatments, and might manifest in several clinical signs, with pain and swelling being the most common symptoms [9]. As for oral and maxillofacial trauma, according to a 5-year study conducted in a hospital in Iran, it was revealed that during the five years, 708 cases of oral and maxillofacial fractures occurred, with a majority of those cases happening in men [10]. In a one-year study conducted by Singaram et al., it was shown that maxillofacial injuries were the most common injury [11] with pain being present in this type of injury $[12,13]$.

Regarding orofacial pain, pain in oral and maxillofacial infection patients, and oral and maxillofacial trauma patients has been known as one of the most experienced clinical signs [13 - 16]. As previously investigated and acknowledged, orofacial pain has been associated with compromised jaw function [17] and aggravated by psychological factors, such as high levels of stress, anxiety, and depression [18]. Regarding stress, alpha-amylase is one of the salivary enzymes secreted by the salivary glands in response to sympathetic nerve stimuli. When the body is exposed to psychological stress, one of the main systems that are activated is the Sympatho-AdrenoMedullary (SAM) system. When this system is active, the level of catecholamines in the blood will increase, and as a result, it will increase the SAA level as well [19]. Therefore, the measurement of the SAA level can be used as an indicator of sympathetic activity due to psychological stressors [20]. Based on this hypothesized correlation, the current study was designed. The objectives of the current study were: 1) to investigate the correlation between pain level and jaw and facial activity limitation, and 2) to investigate the correlation between stress and jaw and facial activity limitation by evaluating the SAA level and pain score of oral and maxillofacial infection and trauma patients.

\section{MATERIALS AND METHODS}

\subsection{Participants and Study Design}

The current study recruited 50 (16 male, 34 female) patients aged 18 to 71 years old (mean: 34.03 , SD: 16.59) with oral and maxilla infection or oral and maxilla trauma that were admitted to the Emergency Unit of Ujung Berung District Hospital, Bandung, Indonesia and were experiencing acute orofacial pain due to oral and maxillofacial infection or oral and maxillofacial trauma. Before the start of the study, ethical clearance was gained from the Universitas Padjadjaran Research Ethics Committee (ethical clearance number 1303/UN6.KEP/EC/2018). For confirmation, every procedure and ethical aspect of the current research have been conducted in full accordance with the World Medical Association Declaration of Helsinki and that all participants gave written consent for their participation in the current study.

Patients' selection was based on two inclusion criteria, the general inclusion criteria and the specific criteria. General inclusion criteria for the current study were: patients who 1) aged 18 years old or older, 2) experienced acute orofacial pain due to the current oral and maxillofacial infection or trauma with no accompanying pain from other body parts, 3) could communicate verbally with the field researcher, 4) did not consume any analgesic agents for the last eight hours, and 5) had never been diagnosed with Temporomandibular Disorders (TMD). As for the specific criteria: 1) patients who were included in the current study were oral and maxilla infection patients with the following criteria: odontogenic origin abscess or cellulitis that involved the maxilla and the mandible area (subperiosteal, submucosa, submandibular space, sublingual and submental space) that was initiated and had been occurring within the last seven days, and 2) as for oral and maxillofacial trauma patients, trauma patients included in the current study were patients with a trauma that causes injury to the soft and hard tissues of the face, mouth and dentoalveolar, such as nasal complex fracture, zygomatic arch fracture, dentoalveolar fracture, mandibular fracture, and maxillary fracture, with no other fracture from other body parts. Patients who happened to consume alcohol in the last 72 hours or who suffered with another oral disease or some other disease in other body parts that might act as pain sources were excluded from the study.

\subsection{Sample Size Calculation}

Sample size calculation is carried out by using the current formula:

$$
\mathrm{n}=\left(\frac{z \alpha+z \beta}{0.5 \ln \frac{1+r}{1-r}}\right)^{2}+3
$$

$\mathrm{N}$ : Sample number

$\mathrm{Z} \alpha$ : Z-score which is a standard normal variate (at $5 \%$ type 1 error, 1.64)

$Z \beta$ : Type 2 error is set at $20 \%$, which is 0.84

$\mathrm{r}$ : a minimal correlation between the quantity of pain and stress and functional activity of the jaw is considered significant and set at 0.5 .

By entering the above values into the formula, the following value is obtained

$$
\mathrm{n}=\left(\frac{1,645+1.280}{0.5 \ln \frac{1+0.5}{1-0.5}}\right)^{2}+3
$$

$\mathrm{n}=23.465 \ldots$ and rounded off into 23

Therefore, the minimum sample size was 23 for each group 
Once the participants agreed to participate, they were asked to sign a written informed consent. Pain level was evaluated by using the Numeric Rating Scale (NRS), the stress level was evaluated by measuring the alpha-amylase salivary level, and the jaw and facial function limitation were evaluated by using the Jaw and Facial Activities Limitation (JFAL) questionnaire.

\subsection{Numeric Rating Scale (NRS)}

The NRS is a numerical scale that ranged from 0 to 10 , with 0 being the state of no pain, whilst 10 is the most intense pain that the patient can imagine. The scoring of this particular scale can be classified into three categories, mild (1 - 3), moderate $(4-6)$, and severe $(7-10)$ [21]. The NRS has been acknowledged for its validity and reliability for pain measurement purposes in several previous studies [22 - 25]. It is also acknowledged for its advantage amongst other pain measurement scales [22].

\subsection{Jaw and Facial Activities Limitation Questionnaire}

Participants were interviewed based on the questions on Jaw and Facial Activities Limitation (JFAL) questionnaire (Fig. 1) to measure jaw and facial activities limitation. The questionnaire consisted of seven questions that measured the level of function limitation experienced by orofacial pain patients, such as mouth opening as well as closing, chewing, swallowing, speaking, lateral movement, and facial expression, such as smiling. Each question was provided with four Likertscale. The questionnaire had been tested for its validity and reliability before the start of the study. The Cronbach's alpha value was 0.80 , and the questions were found to be significantly reliable $(\mathrm{p}<0.05)[26]$.

\subsection{Salivary Alpha-Amylase (SAA) Level}

In the current study, the SAA level was measured by using the cocoro meter (Nipro, Japan). This tool consists of a disposable strip to take saliva samples and a monitor to analyze SAA levels from those samples [18]. Once the measurement of pain and jaw and facial function was completed, the SAA level of the participant was measured by inserting the tip of the cocoro meter strip under the tongue for 30 seconds. The strip was then immediately inserted into the cocoro meter. The level of SAA was displayed on the monitor of the cocoro meter.

\subsection{Statistical Analysis}

All data were gathered and tabulated. The mean value and standard deviation of NRS scores, SAA value, and JFAL scores were calculated by using descriptive analysis. The correlation of the pain level, stress level, and the jaw and facial activity limitation were analyzed by evaluating the r-value of the Spearman correlation test. The significance level was set at $\mathrm{p}<0.05$. All statistical tests were performed by using the SPSS version (IBM) [23].

\section{RESULTS}

The current study evaluated the relationship between the pain level, stress, and jaw and facial activity limitation on 50 patients with oral and maxillofacial infection and oral and maxillofacial trauma. The demographical characteristics, as well as the clinical characteristics of the participants, can be viewed in Table $\mathbf{1}$.

The results of the study revealed that pain levels between participants varied and that more patients experienced moderate to severe pain compared to mild to moderate pain. When calculated, the mean score for the NRS score was set at 5.4. A descriptive analysis of the NRS, the SAA level, and the jaw and facial activity limitation (Fig. 2) revealed that the highest mean NRS mean score was shown by the male patients, and the highest SAA level was experienced by female participants and those who aged between 46 to 72 years old. Even though the female participants showed a higher SAA level, no significant difference was found between female and male participants.

An analysis of the jaw and facial activities limitation questionnaire (Table 2) showed that bringing the teeth in contact (occlusion), moving the jaw laterally, and smiling were the functions that were experienced as highly limited. Opening the mouth was also one of the most complained functions of which the participants felt that the limitation of this particular function was at the mild and moderate level.

Table 1. Distribution of participants based on the diagnosis; Numeric Rating Scale (NRS) score, salivary alpha-amylase level, and Jaw and Facial Activities Limitation (JFAL) questionnaire score.

\begin{tabular}{|c|c|c|c|c|c|}
\hline \multicolumn{2}{|c|}{ Variable } & \multicolumn{2}{|c|}{ Sex } & \multicolumn{2}{|c|}{ Age } \\
\hline & & Male & Female & 18 yo* - 45 yo & 46 yo -72 yo \\
\hline \multirow[t]{2}{*}{ Diagnosis } & Infection & 5 & 20 & 19 & 6 \\
\hline & Trauma & 11 & 14 & 20 & 5 \\
\hline \multirow{2}{*}{$\begin{array}{c}\text { NRS Score } \\
(0-10)\end{array}$} & $0-5$ & 4 & 20 & 18 & 6 \\
\hline & $6-10$ & 12 & 14 & 21 & 5 \\
\hline \multirow[t]{3}{*}{ Salivary alpha-amylase level } & $0-35$ & 13 & 27 & 31 & 9 \\
\hline & $36-70$ & 2 & 4 & 5 & 1 \\
\hline & $>70$ & 1 & 3 & 3 & 1 \\
\hline \multirow{2}{*}{$\begin{array}{l}\text { JFAL Score } \\
\quad(0-21)\end{array}$} & $0-10$ & 11 & 26 & 27 & 10 \\
\hline & $11-21$ & 5 & 8 & 12 & 1 \\
\hline
\end{tabular}

\footnotetext{
*year-old
} 
Name :

Age :

Sex :

Please tick the box that is most appropriate for describing the level of your oral and facial activities limitation due to your orofacial pain!

Due to your orofacial pain:

1. How difficult it is for you to bring your upper teeth and your lower teeth in contact?

$\square$ not at all $\square$ a little bit $\square$ moderately $\square$ a lot

2. How difficult it is for you to speak?

$\square$ not at all $\square$ a little bit $\quad \square$ moderately $\square$ a lot

3. How difficult it is for you to open your mouth?

$\square$ not at all $\square$ a little bit $\square$ moderately $\square$ a lot

4. How difficult it is for you to close your mouth after you open your mouth? $\square$ not at all $\square$ a little bit $\square$ moderately $\square$ a lot

5. How difficult it is for you to swallow (saliva or food)? $\square$ not at all $\square$ a little bit $\square$ moderately $\square$ a lot

6. How difficult it is for you to move your jaw laterally? $\square$ not at all $\square$ a little bit $\square$ moderately $\square$ a lot

7. How difficult it is for you to smile?

$\square$ not at all $\square$ a little bit $\quad \square$ moderately $\square$ a lot

Fig (1). List of questions and answers of the jaw and facial activities limitation questionnaire.

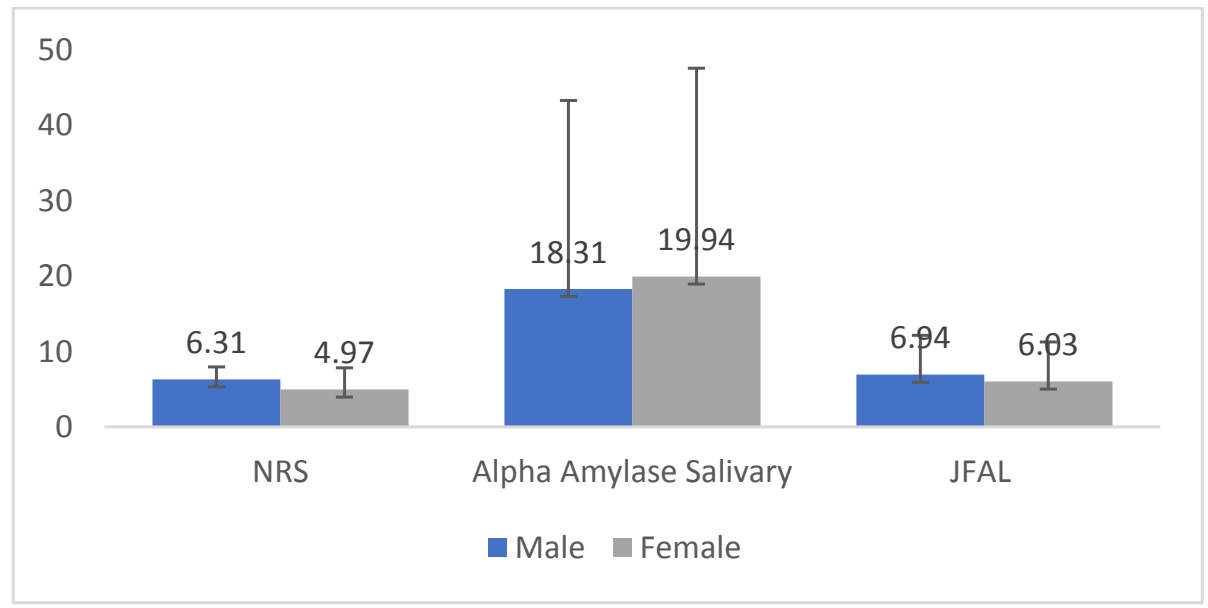

(a) 


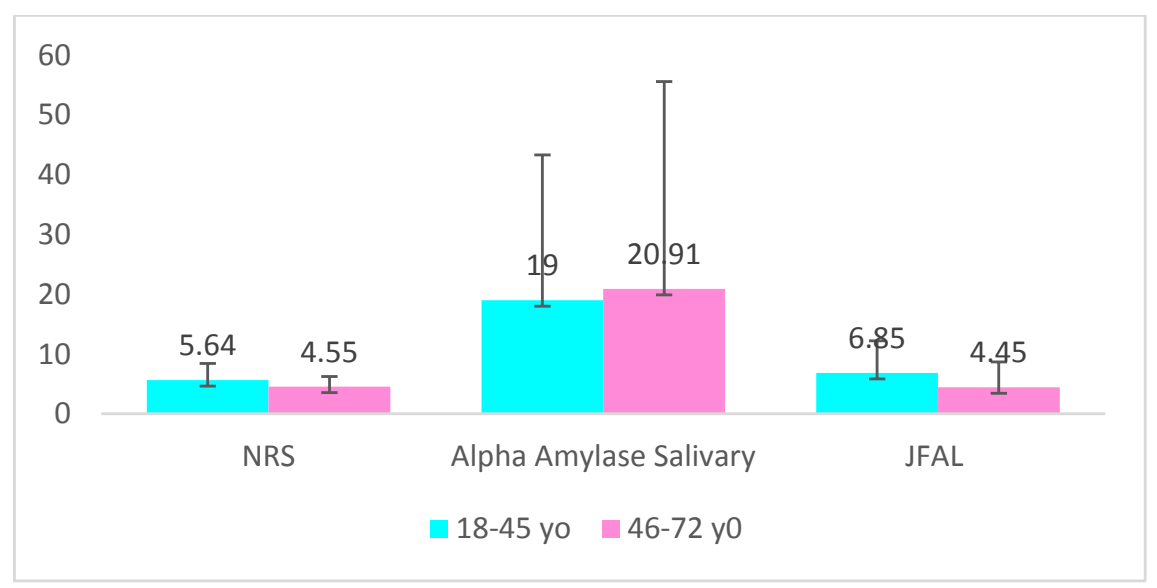

(b)

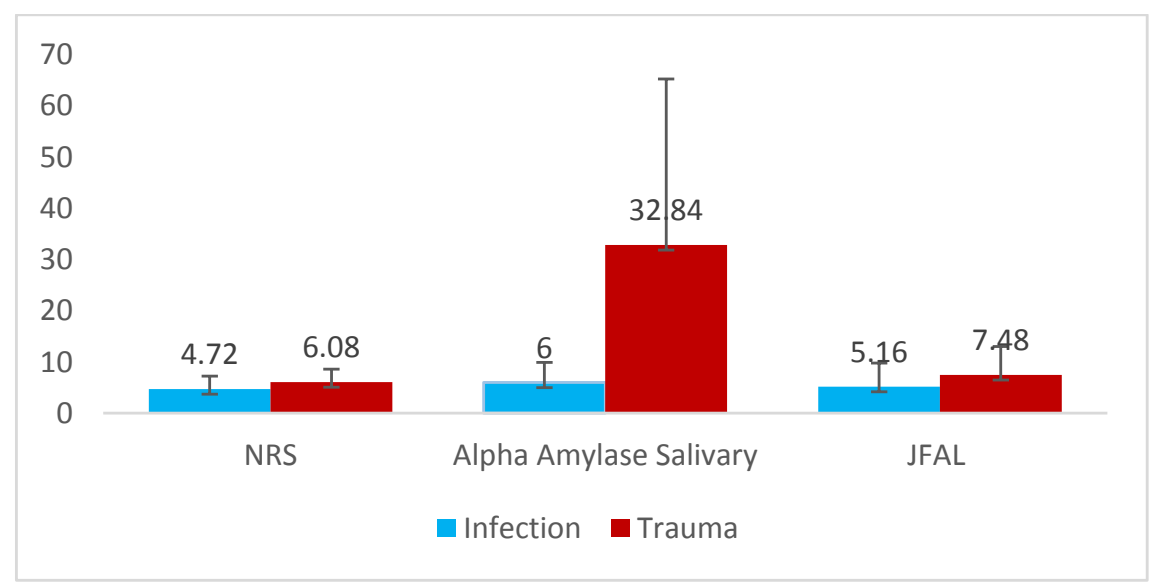

(c)

Fig. (2a,b and c). Mean scores of Numeric Rating Scale (NRS), Salivary alpha-amylase, and Jaw and Facial Activities Limitation (JFAL) based on sex, age, and type of diagnosis.

Table 2. Participant's distribution on Jaw and facial activities limitation description based on the Jaw and Facial Activities Limitation Questionnaire (JFAL).

\begin{tabular}{|c|c|c|c|c|c|c|}
\hline \multirow{2}{*}{ Question } & \multicolumn{5}{|c|}{ Degree of Limitation } & \multirow{2}{*}{ SD* } \\
\cline { 2 - 6 } & Not at all & A little bit & Moderately & A lot & \\
\hline Number 1 & 17 participants (34\%) & 9 participants (18\%) & 10 participants (20\%) & $\mathbf{1 4}$ participants (28\%) & \\
\hline Number 2 & 30 participants (60\%) & 12 participants (24\%) & 5 participants (10\%) & 3 participants (6\%) & 1.42 \\
\hline Number 3 & 22 participants (44\%) & 11 participants (22\%) & 11 participants (22\%) & 6 participants (12\%) & 0.62 & 1.23 \\
\hline Number 4 & 33 participants (66\%) & 6 participants (12\%) & 7 participants (14\%) & 4 participants (8\%) & 0.90 \\
\hline Number 5 & 41 participants (82\%) & 5 participants (10\%) & 4 participants (8\%) & 0 participants (0\%) & 0.64 & 0.26 \\
\hline Number 6 & 23 participants (46\%) & 8 participants (16\%) & 16 participants (12\%) & $\mathbf{1 3}$ participants (26\%) & 1.08 \\
\hline Number 7 & 24 participants (48\%) & 5 participants (10\%) & 9 participants (18\%) & $\mathbf{1 2}$ participants (24\%) & 0.60 \\
\hline
\end{tabular}

\section{*SD $=$ Standard deviation}

As for the correlation analysis, in the current study, no significant correlation was found between sex and pain level, age and pain level, sex and stress level, as well as age and stress level (Table 3). Yet, the orofacial pain level was found to be significantly $(\mathrm{p}<0.01)$ and moderately $(\mathrm{r}=0.555)$ correlated to the jaw and facial activity limitation. Another significant $(\mathrm{p}=0.001)$ correlation with moderate $(\mathrm{r}=0.460)$ correlation was found between stress and jaw and facial activity limitation.

\section{DISCUSSION}

The current study suggested that most patients (52\%) showed a moderate to high NRS score (between 6 and 10). Regarding pain measurement in oral and maxillofacial surgery 
cases, in a study conducted by Boljevic et al., it was shown how high pain intensity $(>5)$ is a common thing experienced by oral and maxillofacial surgery patients. In that study, a high level of pain intensity was found to be associated with clinical complications [13]. The results of the current study also showed that there was no significant difference found between the female NRS mean score and the male NRS mean score, nor a significant correlation between pain level and gender. This particular result is in line with a study conducted by GalvãoMoreira et al. on perceived facial pain. In their study, GalvãoMoreira et al. evaluated morning cortisol level as a pain level indicator, and no significant correlation between gender and cortisol level was found.

Table 3. Results of Spearman correlation analysis and significance level between variables.

\begin{tabular}{|c|c|c|c|}
\hline No. & Correlation & r value & p-value \\
\hline $\mathbf{1}$ & Age and pain level & -0.199 & 0.17 \\
\hline $\mathbf{2}$ & Sex and pain level & -0.246 & 0.09 \\
\hline $\mathbf{3}$ & Age and stress level & -0.067 & 0.64 \\
\hline $\mathbf{4}$ & Sex and stress level & -0.046 & 0.75 \\
\hline $\mathbf{5}$ & Age and jaw and facial activities limitation & -0.175 & 0.22 \\
\hline $\mathbf{6}$ & Sex and jaw and facial activities limitation & -0.081 & 0.58 \\
\hline $\mathbf{7}$ & Pain level and stress level & 0.176 & 0.22 \\
\hline $\mathbf{8}$ & Pain level and jaw and facial activities limitation & $\mathbf{0 . 5 5 5}$ & $<\mathbf{0 . 0 1}$ \\
\hline $\mathbf{9}$ & Stress level and jaw and facial activities & $\mathbf{0 . 4 6 0}$ & $\mathbf{0 . 0 0 1 *}$ \\
\hline
\end{tabular}

As for the SAA, the current study suggested that there was no significant difference found between the SAA level in male participants compared to female participants and that the SAA level was increased along with age. These results are in line with the results of a study conducted by Ahmadi-Motamayel et $a l$. on the level of salivary alpha-amylase activity in patients with symptomatic irreversible pulpitis. In the Study, AhmadiMotamayel et al. revealed that the SAA level was increased along with age [27]. Regarding the correlation between SAA level and age, there have been some results variations [28]. Some studies suggested that there is no correlation between age and SAA level $[29,30]$ whilst some studies suggested that there is a correlation between these variables [27, 31]. Physiological and psychological factors (such as salivary gland development, eating habits, and stress responses that involve the autonomic nervous system and hypothalamus-pituitaryadrenal axis), collection method, type of saliva collected (resting or stimulated) might contribute to these variations [28, 31].

One of the main correlations evaluated in the current study was the correlation between pain level and stress level of the patient. Regarding this, a rather weak, positive $(r=0.176)$ correlation was found between pain level and stress of the participant, regardless of the statistical insignificance $(\mathrm{p}=$ 0.22 ). This positive correlation showed that whenever there is an increase in pain level, an increase in stress level will also be found. This particular result is in line with a review study conducted by Cathcart et al. and a study conducted by Pozzebon et al., who evaluated the relationship between pain and stress. It was stated that pain sensitivity might be increased by the presence of stress and that the pain processing that takes place in the central nervous system might also be affected by stress [32, 33]. Regardless of the correlation found between these two variables, the correlation was statistically insignificant. This might be due to the rather limited sample size. Therefore, a follow-up study that involves more sample size might yield a different result.

Another part of the results of this study revealed a significant positive correlation $(r=0.555, p<0.01)$ between acute orofacial pain level and jaw and facial activity limitation. The fact that jaw and facial activity limitation was increased along with increased pain intensity is in favor of the Pain Adaptation theory. This particular theory suggested that pain experienced by a person will cause limited muscle movement to prevent further injury, which will then improve the recovery process [34]. The results of the current study also revealed that one of the jaw activities that was moderate to severely limited is the ability to open the mouth and this complaint was made by $17(34 \%)$ participants. In a study conducted by Alotaibi et al. on odontogenic infections, it was stated that one of the most common symptoms in patients with odontogenic infection and maxillofacial trauma is trismus $[35,36]$, which is in line with the results of the current study.

In a clinical review by Renton on odontogenic pain, it was stated that odontogenic pain that originates from dental caries develops further and causes pulpal inflammation, which will cause increased pulpal vascularity. This will eventually cause increased pulpal pressure, induce ischemia and sensitivity, and cause dental necrosis. Once dental necrosis occurs, the infection will spread into the surrounding bone and periodontal membrane through the apex, which will then initiate periodontal inflammation and dental abscess in a further stage. Moreover, after the occurrence of a dental abscess, the patient will experience long-lasting pain and pain biting on the tooth [37]. This might be the cause why one of the most interfered jaw activities reported by the participants was "to bring the upper teeth and lower teeth in contact" (Table 3).

Another result obtained from this study is the significant positive correlation between stress level and the limitation of the jaw and facial activities. Regarding psychological stress and jaw and facial activities, our study suggested that previous studies mostly evaluated the contribution of stress to parafunctional activities [38] or the correlation between stress and temporomandibular disorders symptoms [39, 40], but none of the previous studies evaluated the correlation between stress and the jaw and facial activities, as included in the current study. The jaw and facial activities evaluated in the current study involve the jaw muscles during their activities. As it is already known that when a muscle is resting, it is under normal tension (produced by the stimulation of the alpha neurons) that does not lead to muscle fatigue [38]. When a stressor of stress is present, the amygdala sends a signal to the brain stem, and sympathetic adrenergic catecholamines, norepinephrine, and epinephrine will be released to enter the blood flow [41]. The increase of plasma norepinephrine will then increase the production as well the release of SAA produced by the acinar cells of the submandibular and parotid salivary glands [42], which explains the high SAA level in most patients. 
As for the effect it has on the human body, stress has been known for its various impacts on the masticatory muscles. In a study conducted by Tsai et al. on the effect of experimental stress on the masticatory muscles, it was revealed that the electromyography of the masseter, posterior temporalis, and suprahyoid muscles were significantly increased during a stressful task [43]. Stress impacts muscle activity through the reticular system in the hypothalamus and the limbic system in particular by affecting muscle activity. Moreover, the occurrence of stress-induced muscle hyperactivity often results in muscle dysfunction and pain [44]. In the current study, the stress experienced by the patient physiologically might lead to hyperactivity of the facial muscle and result in muscle dysfunction therefore, affecting the activity of the jaw muscles that are responsible for jaw opening, jaw closing, lateral jaw movements, bringing the tooth in contact, as well as smiling.

The psychological effect of stress on facial expression has been the topic of previous studies $[45,46]$. The importance, as well as the involvement of the psychological aspect in orofacial pain, has been acknowledged in the biopsychosocial model of orofacial pain [47 - 49]. Basically, the concept acknowledges that any kind of disease is comprised of the biological, psychological, and social aspects that act as an entity and that every disease or disorder has both the involvement and consequences of these three aspects [47]. Concerning orofacial pain, acknowledging the involvement of the psychological aspect, and incorporating it within the treatment plan is of importance.

\section{CONCLUSION}

In conclusion, the current study suggested a significant positive correlation between orofacial pain level and jaw and facial activity limitation as well as stress level and jaw and facial activity limitation. Yet, the evaluation of an increased number of samples might yield different results and provide the possibility of further evaluation. A further study evaluating these correlations based on gender, age, as well as different types of patients might provide a scientific explanation for the current study findings.

\section{ETHICS APPROVAL AND CONSENT TO PARTI- CIPATE}

Ethics approval was obtained from the Research Ethics Committee of Universitas Padjadjaran, Indonesia (ethical clearance number 1303/UN6.KEP/EC/2018).

\section{HUMAN AND ANIMAL RIGHTS}

No animals were used in this research. All research procedures on humans were followed in accordance with the ethical standards of the committee responsible for human experimentation (institutional and national), and with the Helsinki Declaration of 1975, as revised in 2008 (http://www.wma.net/en/20activities/10ethics/10helsinki/).

\section{CONSENT FOR PUBLICATION}

All participants signed an informed consent regarding their participation in the study and their agreement regarding the publication of the data was also gained in the current study.

\section{AVAILABILITY OF DATA AND MATERIALS}

The data supporting the findings of the current study are available from the corresponding author [T.M] on reasonable request.

\section{FUNDING}

The current study was funded by the University of Padjadjaran through the Riset Fundamental Unpad (RFU) research grant.

\section{CONFLICT OF INTEREST}

The authors declare no conflict of interest, financial or otherwise.

\section{ACKNOWLEDGEMENTS}

All authors would like to acknowledge the staff of the Emergency Unit of Ujung Berung District Hospital, Bandung, Indonesia, for their kind assistance and help during the study period.

\section{REFERENCES}

[1] Chung JW, Kim JH, Kim HD, Kho HS, Kim YK, Chung SC. Chronic orofacial pain among Korean elders: prevalence, and impact using the graded chronic pain scale. Pain 2004; 112(1-2): 164-70. [http://dx.doi.org/10.1016/j.pain.2004.08.014] [PMID: 15494197]

[2] Von Korff M, Ormel J, Keefe FJ, Dworkin SF. Grading the severity of chronic pain. Pain 1992; 50(2): 133-49.

[http://dx.doi.org/10.1016/0304-3959(92)90154-4] [PMID: 1408309]

[3] Moharamzadeh K. Diseases and conditions in dentistry: an evidencebased reference. John Wiley \& Sons 2018. [http://dx.doi.org/10.1002/9781119312093]

[4] Maulina $T$. The management of orofacial pain in developing countries: The current challenges. Dent Open J 2017; 4(1): 1-4. [http://dx.doi.org/10.17140/DOJ-4-130]

[5] Svensson L, Hakeberg M, Wide U. Dental pain and oral health-related quality of life in individuals with severe dental anxiety. Acta Odontol Scand 2018; 76(6): 401-6.

[http://dx.doi.org/10.1080/00016357.2018.1473892]

[PMID: 29782197]

[6] Locker D, Grushka M. The impact of dental and facial pain. J Dent Res 1987; 66(9): 1414-7.

[http://dx.doi.org/10.1177/00220345870660090101] [PMID: 3476612]

[7] Locker D, Grushka M. Prevalence of oral and facial pain and discomfort: preliminary results of a mail survey. Community Dent Oral Epidemiol 1987; 15(3): 169-72.

[http://dx.doi.org/10.1111/j.1600-0528.1987.tb00508.x] [PMID: 3474103]

[8] Ogle OE. Odontogenic Infections. Dent Clin North Am 2017; 61(2): 235-52.

[http://dx.doi.org/10.1016/j.cden.2016.11.004] [PMID: 28317564]

[9] Robertson D P, Keys W, Rautemaa-Richardson R, Burns R, Smith A J. Management of severe acute dental infections. bmj 2015; 350: h1300.

[10] Akhlaghi F, Mafi N, Bastami F. Prevalence of maxillofacial fractures and related factors: A five-year retrospective study. Trauma Mon 2019; 24(4): 1-4.

[http://dx.doi.org/10.5812/traumamon.83974]

[11] Singaram M, G SV, Udhayakumar RK. Prevalence, pattern, etiology, and management of maxillofacial trauma in a developing country: a retrospective study. J Korean Assoc Oral Maxillofac Surg 2016; 42(4): 174-81.

[http://dx.doi.org/10.5125/jkaoms.2016.42.4.174] [PMID: 27595083]

[12] Anyanechi CE, Saheeb BD. Inflammatory morbidity due to compound mandibular body fractures: Does it have a relationship with treatment outcome? Med Princ Pract 2015; 24(3): 238-43.

[http://dx.doi.org/10.1159/000376581] [PMID: 25791420]

[13] Boljevic T, Vukcevic B, Pesic Z, Boljevic A. The quality of life of patients with surgically treated mandibular fractures and the relationship of the post-traumatic pain and trismus with the postoperative complications: A prospective study. Medicina (Kaunas) 
2019; 55(4): 109.

[http://dx.doi.org/10.3390/medicina55040109] [PMID: 30999698]

[14] Shweta; Prakash, S. K., Dental abscess: A microbiological review. Dent Res J 2013; 10(5): 585-91.

[15] An J, Madeo J, Singhal M. Ludwig Angina. Treasure Islands, FL: StatPearls Publishing 2019.https://www.ncbi.nlm.nih.gov/books/NBK482354/

[16] Koray M, Tosun T. 2019.https://www.intechopen.com/books/trauma-in-dentistry/oral-muc osal-trauma-and-injuries

[17] Chantaracherd P, John MT, Hodges JS, Schiffman EL. Temporomandibular joint disorders' impact on pain, function, and disability. J Dent Res 2015; 94(3)(Suppl.): 79S-86S. [http://dx.doi.org/10.1177/0022034514565793] [PMID: 25572112]

[18] Yamaguchi M, Deguchi M, Wakasugi J, et al. Hand-held monitor of sympathetic nervous system using salivary amylase activity and its validation by driver fatigue assessment. Biosens Bioelectron 2006; 21(7): 1007-14

[http://dx.doi.org/10.1016/j.bios.2005.03.014] [PMID: 15871919]

[19] Chatterton RT Jr, Vogelsong KM, Lu YC, Ellman AB, Hudgens GA. Salivary alpha-amylase as a measure of endogenous adrenergic activity. Clin Physiol 1996; 16(4): 433-48.

[http://dx.doi.org/10.1111/j.1475-097X.1996.tb00731.x] [PMID: 8842578]

[20] Takai N, Yamaguchi M, Aragaki T, Eto K, Uchihashi K, Nishikawa Y. Effect of psychological stress on the salivary cortisol and amylase levels in healthy young adults. Arch Oral Biol 2004; 49(12): 963-8. [http://dx.doi.org/10.1016/j.archoralbio.2004.06.007] [PMID: 15485637]

[21] Jensen MP. 2011.https://www.oxfordclinicalpsych.com/view/10.1093 /med:psych/9780199772377.001.0001/med-9780199772377interactive-pdf-002.pdf

[22] Ferreira-Valente MA, Pais-Ribeiro JL, Jensen MP. Validity of four pain intensity rating scales. Pain 2011; 152(10): 2399-404.

[http://dx.doi.org/10.1016/j.pain.2011.07.005] [PMID: 21856077]

[23] Castarlenas E, Jensen MP, von Baeyer CL, Miró J. Psychometric properties of the numerical rating scale to assess self-reported pain intensity in children and adolescents. Clin J Pain 2017; 33(4): 376-83. [http://dx.doi.org/10.1097/AJP.0000000000000406] [PMID: 27518484]

[24] Alghadir AH, Anwer S, Iqbal A, Iqbal ZA. Test-retest reliability, validity, and minimum detectable change of visual analog, numerical rating, and verbal rating scales for measurement of osteoarthritic knee pain. J Pain Res 2018; 11: 851-6.

[http://dx.doi.org/10.2147/JPR.S158847] [PMID: 29731662]

[25] Haefeli M, Elfering A. Pain assessment. Eur Spine J 2006; 15(1)(Suppl. 1): S17-24.

[http://dx.doi.org/10.1007/s00586-005-1044-x] [PMID: 16320034]

[26] Maulina T, Shafira M, Wulansari D, Nurwiadh A. Validation of the jaw and facial activities limitation (JFAL) questionnaire for orofacial pain patients. Open Dent J 2020; 14: 305-12.

[27] Ahmadi-Motamayel F, Shahriari S, Goodarzi MT, Moghimbeigi A, Jazaeri M, Babaei P. The relationship between the level of salivary alpha amylase activity and pain severity in patients with symptomatic irreversible pulpitis. Restor Dent Endod 2013; 38(3): 141-5. [http://dx.doi.org/10.5395/rde.2013.38.3.141] [PMID: 24010080]

[28] Yang Z-M, Chen L-H, Zhang M, et al. Age differences of salivary alpha-amylase levels of basal and acute responses to citric acid stimulation between chinese children and adults. Front Physiol 2015; 6(240): 340.

[http://dx.doi.org/10.3389/fphys.2015.00340] [PMID: 26635626]

[29] Almela M, Hidalgo V, Villada C, et al. Salivary alpha-amylase response to acute psychosocial stress: the impact of age. Biol Psychol 2011; 87(3): 421-9.

[http://dx.doi.org/10.1016/j.biopsycho.2011.05.008] [PMID: 21664412]

[30] Nassar M, Hiraishi N, Islam MS, Otsuki M, Tagami J. Age-related changes in salivary biomarkers. J Dent Sci 2014; 9(1): 85-90. [http://dx.doi.org/10.1016/j.jds.2013.11.002]

[31] Stroud LR, Foster E, Papandonatos GD, et al. Stress response and the adolescent transition: performance versus peer rejection stressors. Dev Psychopathol 2009; 21(1): 47-68.

[http://dx.doi.org/10.1017/S0954579409000042] [PMID: 19144222]
[32] Cathcart S, Winefield AH, Lushington K, Rolan P. Stress and tensiontype headache mechanisms. Cephalalgia 2010; 30(10): 1250-67. [http://dx.doi.org/10.1177/0333102410362927] [PMID: 20873360]

[33] Pozzebon D, Piccin CF, da Silva AMT, Corrêa ECR. Relationship among perceived stress, anxiety, depression and craniocervical pain in nursing professionals under stress at work. Fisoter Mov Curitiba 2016; 29(2): 377-85.

[http://dx.doi.org/10.1590/0103-5150.029.002.AO17]

[34] Peck CC, Murray GM, Gerzina TM. How does pain affect jaw muscle activity? The integrated pain adaptation model. Aust Dent J 2008; 53(3): 201-7.

[http://dx.doi.org/10.1111/j.1834-7819.2008.00050.x]

[PMID: 18782363]

[35] Alotaibi N, Cloutier L, Khaldoun E, Bois E, Chirat M, Salvan D. Criteria for admission of odontogenic infections at high risk of deep neck space infection. Eur Ann Otorhinolaryngol Head Neck Dis 2015; 132(5): 261-4.

[http://dx.doi.org/10.1016/j.anorl.2015.08.007] [PMID: 26347337]

[36] Borba AM, Porto AN, Santini A, et al. The effect of facial fractures on mouth opening range: a case series. Revista Sul-Brasil Odontologia 2017; 14(3): 142-6.

[37] Renton T. Dental (odontogenic) pain. Rev Pain 2011; 5(1): 2-7. [http://dx.doi.org/10.1177/204946371100500102] [PMID: 26527224]

[38] Wieckiewicz M, Paradowska-Stolarz A, Wieckiewicz W. Psychosocial aspects of bruxism: the most paramount factor influencing teeth grinding. BioMed Res Int 2014; 2014469187

[http://dx.doi.org/10.1155/2014/469187] [PMID: 25101282]

[39] Augusto VG, Perina KCB, Penha DSG, Dos Santos DCA, Oliveira VAS. Tempromandibular dysfunction, stress, and common mental disorder in university students. Acta Ortop Bras 2016; 24(6): 330-3. [http://dx.doi.org/10.1590/1413-785220162406162873] [PMID: 28924361]

[40] Gawade KD, Vardharajulu G. Prevalance of correlation between temporomandibular dysfunction and occupational stress in white collar professionals. J Health Res Rev 2019; 6: 62-6.

[http://dx.doi.org/10.4103/jhrr.jhrr_21_19]

[41] Hannibal KE, Bishop MD. Chronic stress, cortisol dysfunction, and pain: a psychoneuroendocrine rationale for stress management in pain rehabilitation. Phys Ther 2014; 94(12): 1816-25.

[http://dx.doi.org/10.2522/ptj.20130597] [PMID: 25035267]

[42] Chaturvedi Y, Chaturvedy S, Marwah N, Chaturvedi S, Agarwal S, Agarwal N. Salivary cortisol and alpha-amylase-Biomarkers of stress in children undergoing extraction: An in vivo study. Int J Clin Pediatr Dent 2018; 11(3): 214-8.

[http://dx.doi.org/10.5005/jp-journals-10005-1514] [PMID: 30131644]

[43] Tsai C-M, Chou S-L, Gale E-N, McCall WD Jr. Human masticatory muscle activity and jaw position under experimental stress. J Oral Rehabil 2002; 29(1): 44-51.

[http://dx.doi.org/10.1046/j.1365-2842.2002.00810.x]

[PMID: 11844031]

[44] Chisnoiu A, Lascu L, Pascu L, Georgiu C, Chisnoiu R. Emotional stress evaluation in patients with temporomandibular joint disorder. Human Veterin Med 2015; 7(2): 104-7.

[45] Mayo LM, Heilig M. In the face of stress: Interpreting individual differences in stress-induced facial expressions. Neurobiol Stress 2019; 10100166

[http://dx.doi.org/10.1016/j.ynstr.2019.100166] [PMID: 31193535]

[46] Creemers DHM, Scholte RHJ, Engels RCME, Pieters S, Wiers RW Acute stress increases implicit depression and decreases implicit selfesteem. J Exp Psychopathol 2013; 4(2): 118-32. [http://dx.doi.org/10.5127/jep.025411]

[47] Ohrbach R, Durham J. Biopsychosocial aspects of orofacial pain. In: Farah CS, Balasubramaniam R, McCullough M J, Eds. Contemporary Oral Medicine. Switzerlands: Springer International Publishing 2019. [http://dx.doi.org/10.1007/978-3-319-72303-7_37]

[48] Campi L B, Camparis C M, Jordani P J, Gonçalves D A d G. In uence of biopsychosocial approaches and self-care to control chronic pain and temporomandibular disorders. Rev Dor São Paulo 2013; 14(3): 219-22.

[49] Sharma S, Breckons M, Brönnimann Lambelet B, et al. Challenges in the clinical implementation of a biopsychosocial model for assessment and management of orofacial pain. J Oral Rehabil 2020; 47(1): 87-100. [http://dx.doi.org/10.1111/joor.12871] [PMID: 31398261]

This is an open access article distributed under the terms of the Creative Commons Attribution 4.0 International Public License (CC-BY 4.0), a copy of which is available at: https://creativecommons.org/licenses/by/4.0/legalcode. This license permits unrestricted use, distribution, and reproduction in any medium, provided the original author and source are credited. 